\title{
Investigation of microorganisms associated with the spoilage of onions around dutsinma metropolis
}

\begin{abstract}
The study was conducted to investigate the microorganisms associated with the spoilage of onion bulbs around Dutsinma metropolis. A total of 100 samples were collected from Hayin Gada and Wednesday Markets. Culture, Gram staining and characterization were done for analyses. The bacteria species isolated were Staphylococcus sp, Bacillus sp, Pseudomonas sp, and Esherichia coli, while the fungi were Aspergillus sp, Mucor and Yeast. Esherichia coli had the highest frequency of occurrence $(25.00 \%)$ and the lowest was Pseudomonas sp $(9.38 \%)$ whereas Aspergillus sp had the highest frequency of occurrence (18.75\%) and the lowest was Mucor (6.25\%). The biochemical test revealed that Bacillus sp and Staphylococcus sp were Catalase and Coagulase positive while Pseudomonas sp and Esherichia coli were Coagulase negative. Sensitivity test confirmed that Staphylococcus sp was resistant to Chloramphenicol, Septrin, Amoxicillin, Gentamicin, Streptomycin, Tarivid, Augmentin, Pefloxacin, Sparfloxacine, and Ciprofloxacin, antibiotics while Bacillus sp, Esherichia coli and Pseudomonas sp were sensitive to the antibiotics
\end{abstract}

Keywords: investigation, microorganisms, spoilage, onions, dutsinma
Volume 2 Issue 4 - 2017

\author{
Orpin JB, Yusuf Z, Mzungu I, Orpin CA \\ Department of Biological Sciences, Federal University, Nigeria
}

Correspondence: Orpin JB, Department of Biological Sciences Federal University, Dutsinma, PMB 500I, Dutsinma, Nigeria, Email jorpin@fudutsinma.edu.ng

Received: October 06, 2017 | Published: December 20, 2017

\section{Introduction}

Total or since ancient times, onions (Allium cepa, L.) have been an important dietary resource and have also been of interest for medical purposes. ${ }^{1}$ Traditionally, onions and plants belonging to the Allium genus have been used as an herbal remedy for a wide range of ailments, due to their association with many pharmacological effects. ${ }^{2,3}$ Biological effects attributed to onions have been commonly ascribed to the volatile sulfur-containing compounds, such as thiosulfinates, mainly responsible for the characteristic taste, aroma and lachrymatory effects. ${ }^{4}$ These compounds are formed from cysteine sulfoxide precursors and the effect of the enzyme alliinase which is released from cell vacuoles when tissues are damaged. ${ }^{5}$ However, these volatile products are highly unstable and recently, attention has been focused on the effects of phenolic compounds, such as flavonoids, which are more stable. ${ }^{6}$ Onion is known for being a good natural source of flavonoids mainly represented by the flavonols - quercetin and kaempferol, which are present as their glycosides. ${ }^{7}$ Protection of food from pathogens and spoilage organisms has been traditionally achieved by chemical methods, but during recent years there has been an increase in consumer interest in developing Onion which contain a low level or are free of chemical preservatives. ${ }^{8}$ The emergence of pathogens which are resistant to classical preservatives has also created an urgent necessity to find alternative antimicrobial agents. ${ }^{9}$ In consequence, the food industry is interested in developing natural components for the partial replacement of synthetic antimicrobials. ${ }^{10}$ Onions can be considered as a good source of natural additives to retard food deterioration. ${ }^{11}$ Numerous benefits have been attributed to onions including prevention of cancer and cardiovascular disorders, reduction in the blood levels of cholesterol, reduction in osteoporosis. ${ }^{12}$ Reduction in stomach ulcers, inhibition of the proliferation of cultured ovarian, breast and colon cancer cells, inhibition of platelets-mediated thrombosis, prevention of inflammatory processes associated with asthma, treatment of fever, common cold, cough, sore throat and its use as an antimicrobial agent. ${ }^{13}$ Onions are packed locally in baskets and jute bags. These packaging materials come from palm, bamboo and fibrous jute trees. However these materials provide no barriers of dust, and can easily be crushed which might lead to damage of the onions. During storage, some losses occur due to sprouting, drying and rotting. ${ }^{14}$ Bulb rots are a common cause of onion loss during storage. They are caused by microorganisms particularly fungi. The black mould disease caused by Aspergillus niger is a limiting factor in onion production worldwide. ${ }^{15}$ Aspergillus niger has been reported to survive between onion crops as a soil saprophyte in or on bulbs in field or storage and is ubiquitous in nature. The fungus invades bulbs of onions in field or storage whenever they find injured tissues by producing various enzymes or toxins. ${ }^{16}$ Association of Aspergillus niger with onion seeds produced in hot climates and their transmission from soil and naturally-contaminated seeds to onion seedlings cause $30-80 \%$ loss or spoilage of onion bulbs. ${ }^{17}$

\section{Aim and objectives}

The aim of this research work is to investigate the Microorganisms associated with the spoilage of onions around Dutsinma metropolis with the following objectives:

i) To isolate the Microorganisms responsible for causing onions spoilage

ii) To identify the Microorganisms responsible for causing onions spoilage

iii) To characterize the Microorganisms responsible for the spoilage of onions using biochemical test.

\section{Justification}

This is an investigation of public health significance by determining the risk factor posed to the consumers of spoilt onions, as to suggest appropriate control measures and possible solutions in countering spoilage and storage. 


\section{Statement of the research problem}

This research is going to identify the problems which are encountered when spoilage occurs in onion. Everyday vegetables are being consumed in massive amounts. The onion that is affected by microbes or contaminated by microbes when consumed leads to very severe health problems. These microbes that enhance this spoilage are Streptococcus pyrogenes, Esherishia coli, Pseudomonas aeroginosa, Morgorella morgonii, Staphylococcus aureus, Staphylococcus saprophyticus, Bacillus pumilis, Bacillus lensus, Staphylococcus capilis, Streptococcus sciuri, Bacilus lensus, bacillus antracis, bacillus subtilis, streptococcus equines, Mucor, Yeast, Aspergillus niger, Aspergillus flavus, Fusarium oxysporum, Penicillium digitatum. The proper storage of onions makes it available all year that is why this research is being carried out to minimize the spoilage of onions if possible.

\section{Material and method}

The study was conducted in Dutsinma Local Government Area, Katsina State. It is located on Latitude 12o 27'18'N and longitude 7o 29 '29' $\mathrm{E}$ and has its headquarters in the town of Dutsinma. It has an estimated area of $527 \mathrm{~km}^{2}(203 \mathrm{sqkm})$ and a population of 169,671 as at 2006 census. $^{18}$ The population and activities in the local government area have increased in the last 3 years which may be due to the establishment of the new Federal University . The Local Government is bounded by Kurfi and Charanchi Local Governments to the North, Kankia Local Government to the East, Safana and Dan- Musa Local Governments to the West, and Matazu Local Government to the Southeast. The people are predominantly farmers, cattle rearers and traders (Figure 1).

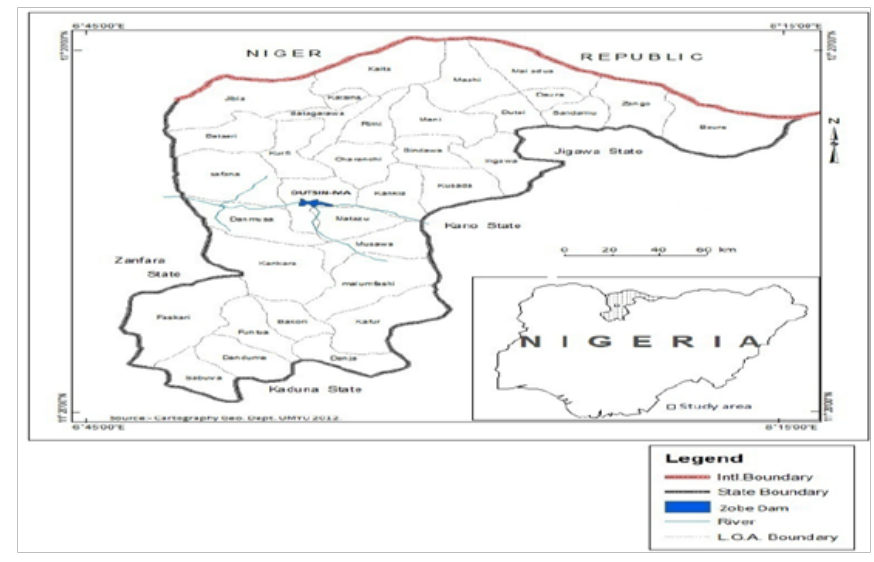

Figure 1 Map of Katsina locating Dutsinma at the centre.

\section{Sample collection}

The onion bulbs were randomly selected from two different markets which include; Wednesday market, and Hayin gada market, packaged in different sterile polythene bags and transported to the Microbiology Laboratory of the Department of Biological Sciences Federal University Dutsinma for analysis.

\section{Material sterilization}

Different laboratory apparatus was used for the research; the apparatus was washed with detergent, rinsed with clean water and then dried. This was followed with a proper sterilization of the apparatus in a hot air oven at high temperature of about $1600 \mathrm{C}$ for 1hour (60 minutes). The materials are petridishes, test tubes, conical flask, a beaker and universal bottles.

\section{Media preparation}

The media used for the isolation and characterization are Sabouraud dextrose agar, nutrient agar, nutrient broth, MacCkonkey, Eosin methycylene blue, Pepton water, Urea agar, Plate count, Citrate agar, Agar agar, Triple sugar iron agar, Methyl red and Voges prosker respectively, and was prepared according to manufacturer's instructions.

\section{Isolation of bacteria and fungi}

\section{Serial dilution and sample preparation}

$70 \%$ of alcohol was used to wipe the surface of the spoiled onion bulb. About $1 \mathrm{~g}$ of the spoiled onion fruit was cut using a sterile razor blade from each of the sample and it was transferred separately into a sterile motor and pestle, sterile distilled water was added into the motor, it was then crushed, $1 \mathrm{ml}$ of the sample was added into a $9 \mathrm{ml}$ of the sterile Nutrient broth in a Universal bottles for each sample, then the samples was allowed to stay for $15 \mathrm{~min} .1 \mathrm{ml}$ from each of the test tube was used to carried out serial dilution for each sample from 101-105.

\section{Inoculation and incubation}

For bacteria, about $0.5 \mathrm{ml}$ of the aliquot from serial dilution of the sample was added in to the media (i.e. Nutrient, MacCkonkey and Eosin methycylene blue Agar respectively), and each media was poured in to sterile Petri dish using sterile storage. It was then allowed to solidify. The sample procedure was repeated for the other sample. Then the inoculated plates were incubated inverted at 370C for $24 \mathrm{hrs}$. For fungi, antibiotic (Chloramphenicol) was added to the media before it cools and solidifies to prevent the growth of bacteria, the same procedure with the bacteria was used. The plates was then be incubated at room temperature for 5 to 7 days.

\section{Microbial colony count}

Bacterial and fungal count was carried out on each of the plate to determine the number of bacterial and fungal growth. This was obtained by counting the whole plate and using the number obtained to multiply by the dilution factor.

\section{Macroscopy and colonial identification}

Characterization and identification of the colony isolates was achieved by initial morphological examination of the colonies in the plate (macroscopy) for colonial appearance, size, elevation, form, edge, consistency, colour, opacity, heamolysis and pigmentation hence result was recorded. The isolates were identified and characterized based on their cultural characteristics, gram reaction and biochemical reaction as follows:

\section{Identification of bacteria and fungi (Gram reaction):}

This was carried out to differentiate gram positive from gram negative organisms..$^{19} \mathrm{~A}$ drop of water was placed on a clean slide and a speck of bacterial growth was taken from the culture. The speck was emulsified on the slide to make a thin smear. The smear was then being passed over a flame to heat fix. It was then flooded with crystal violet for 60 seconds, washed with distilled water and iodine was added for 30seconds, washed with distilled water and decolonized 
with alcohol. The smear was finally flooded with safranin to counter stain for 60 seconds. It will then be washed with distilled water and allowed to air dry. Oil immersion was used and viewed at X100 objective lens. Purple coloration donated gram positive while red donated gram negative. For fungi: Little portion of the fungal growth was placed on a clean glass slide, a drop of the Lactophenol Cotton Blue (LPCB) was added, the speck was emulsified on the slide and viewed at X10 and X40 objective lens.

\section{Characterization of bacteria (Biochemical Tests)}

i. Motility test: Motility test is aimed at identifying motile bacteria, it was carried out as described by, ${ }^{19,20}$ motility can sometimes be referred to as the way an organism grow on solid media, and it determine the presence or absence of flagella. Tubes containing the motility medium were inoculated by making a fine stab with a loopful of the culture to a depth of $1-2 \mathrm{~cm}$ and were then incubated at $370 \mathrm{C}$ for $48 \mathrm{hrs}$. Motility is observed by spreading of the organism outwards from the stab area.

ii. Catalase test: This was used to differentiate those bacteria that produce enzyme Catalase. Catalase test was carried out as described by. ${ }^{19}$ A little portion of the bacterial growth was transferred with a sterilized wire loop to a drop of hydrogen peroxide on a clean glass slide. The presence of catalyses observed by bubbling indicated a positive test result while absence of bubble indicated negative test result of bacteria.

iii. Indole test: This test was carried out for Indole production by test organism which is important in identifying enterobacteria. The test was carried out as described by. ${ }^{19} \mathrm{~A}$ little portion of each isolate was inoculated onto $5 \mathrm{ml}$ of sterile peptone-water enriched with $1 \%$ tryptophan and incubated at $370 \mathrm{C}$ for 24 hours. To the culture, $0.5 \mathrm{ml}$ of Kovac's reagent was added and gently stirred. A red colour indicated positive result while a yellow colour indicated negative test result of bacteria.

iv. Citrate utilization test: This test is based on the ability of an organism to use citrate as it is source of carbon.A little portion of each isolate was inoculated into Koser's citrate medium and incubated at 370C for 72 hours. A positive citrate test was confirmed by formation of bright blue color while the initial green color of the medium indicates a negative test. ${ }^{19}$

v. Methyl Red (MR): MR test was carried out to identify Enterobacteria based on the ability to produce and maintain stable end product from glucose fermentation. It was carried out as described by (Ochei and Kolhatkar, 2000). A little portion of each isolate was inoculated into the glucose phosphate peptone water medium and was incubated at $370 \mathrm{C}$ for 48 hours. Few drops of methyl red were added to the culture. MR positive was indicated by red color.

\section{Antibacterial sensitivity testing}

The antibacterial sensitivity test was used to determine the susceptibility of various bacterial species to various antibiotics and synthetic agents. A standardized disk diffusion method was used; antibiotic susceptibility testing and the zone size interpretation chart were used for the determination of the bacterial sensitive to the antibiotics selected. The commercially prepared paper disk was impregnated with the various antibiotics that will be assessed against the isolates; gentamycin $(10 \mu \mathrm{g})$, streptomycin $(10 \mu \mathrm{g})$, septrin
$(30 \mu \mathrm{g})$, chloramphenicol $(30 \mu \mathrm{g})$, ciproflaxin $(10 \mu \mathrm{g})$, ampiclox $(30 \mu \mathrm{g})$, erythromycin $(10 \mu \mathrm{g})$ and ampicilin $(30 \mu \mathrm{g})$. Each inoculums of bacterial isolates was grown in separate plates at $37^{\circ} \mathrm{C}$ in Mueller Hilton broth (agar plates) for 18hours, with shaking and subsequently diluted to an optical density of $0.1(0.5 \mathrm{Mc}$ Farland standard $)$ and stored at $4^{\circ} \mathrm{c}$. The paper disk was gently but firmly placed on the inoculated plates using sterile forceps. The plates were incubated at $37^{\circ} \mathrm{c}$ for 24 hours after which zones of inhibition was measured and interpreted. Results obtained were classified as resistant or sensitive.

\section{Statistical analysis}

The simple percentage was used as a statistical tool to determine the occurrence frequency of bacteria and fungi isolated from spoilt onions around Dutsinma metropolis.

\section{Results}

Data from (Table 1) show the total colony count in Colony Forming Unit (cfu/g) for twenty (20) collected from Wednesday and Hayin Gada Markets respectively of various bacteria and fungi obtained from the spoilt onion, the result shows the highest bacteria colony observed in Abe (Bacteria Isolated from Hayin Gada Market) was $5.92 \mathrm{X} 105 \mathrm{cfu} / \mathrm{ml}$ and the lowest was $1.04 \mathrm{X} 105 \mathrm{cfu} /$ $\mathrm{ml}$, the highest colony observed in Afe (Fungi Isolated from Hayin Gada Market) was $1.8 \mathrm{X} 105 \mathrm{cfu} / \mathrm{ml}$ and the lowest was $1.1 \mathrm{X} 105 \mathrm{cfu} /$ $\mathrm{ml}$. While in Bbe (Bacteria Isolated from Wednesday Market) the highest colony observed was $5.4 \mathrm{X} 105 \mathrm{cfu} / \mathrm{ml}$ and the lowest colony was $1.32 \mathrm{X} 105 \mathrm{cfu} / \mathrm{ml}$, the highest colony observed in Bfe (Fungi Isolated from Wednesday Market) was $5.8 \mathrm{X} 105 \mathrm{cfu} / \mathrm{ml}$ and the lowest colony observed was $1.0 \mathrm{X} 105 \mathrm{cfu} / \mathrm{ml}$. Data from (Table 2) show the frequency of occurrence of bacteria and fungi isolated from the onion samples, from the two sites and the percentages of occurrence of each bacterium and fungus isolated, identified and characterized. The percentage of occurrence of bacteria and fungi isolated from the samples was highest in E.coli with $25.00 \%$ which probably arose from the use of water during harvesting, the presence of Staphylococcus sp and Aspergillus sp (18.75\%) due to contamination from spores carried in the air. Bacillus sp showed $12.50 \%$ which may be due to post harvest handling. Pseudomonas sp, Yeast and Mucor showed, 9.38\%, 9.38\%, and $6.25 \%$ respectively, probably due to environmental conditions, state of handling, processing, and storage of the onions. Data from (Table 3 ) show the results of Biochemical tests from the spoilt onion samples collected from Wednesday and Hayin gada Markets including for Esherichia coli, Pseudomonas sp, Staphylococcus sp, and Bacillus sp. E.coli is a Gram negative rod, it is motile, positive in Catalase, methyl red, Indole and negative in Citrate, and Coagulase. Bacillus sp Gram positive rod, and Staphylococcus sp Gram positive cocci and were all Catalase and Coagulase positive, while Pseudomonas sp Gram negative rod, positive in Catalase, and Citrate it is Motile and negative in methyl red, Indole, and Coagulase.

Table 4 show the fungi identified and characterized, from the spoilt onion samples including Aspergillus sp, Yeast, and Mucor. Mucor appeared whitish on Sabourand Dextrose Agar plate and thick non septate hyphae on microscope, Yeast appeared as small, creamy or whitish colonies that were somewhat more raised than bacteria colonies. Aspergillus sp appeared black colonies with whitish edges. Data from (Table 5) show the Antibiotics sensitivity of bacteria isolates, Pseudomonas $s p$ recorded the highest sensitivity to all the antibiotics, followed by Esherichia coli which also had no resistance to any of the antibiotics. Bacillus $s p$ was sensitive to all the antibiotics except Chloramphenicol, Tarivid, Augmentin and 
Sparfloxacine. While Staphylococcus $s p$ had the highest resistance to all the antibiotics used because there was no growth in the immediate area around the disc used.

Table I Total colony count from samples collected from hayin gada and wednesday market

\begin{tabular}{lll}
\hline S/N & Sites & Colony count \\
\hline 1 & Abe & $5.2 \times 10^{5}$ \\
2 & Abe & $5.0 \times 10^{5}$ \\
3 & Abe & $1.2 \times 10^{5}$ \\
4 & Abe & $5.92 \times 10^{5}$ \\
5 & Abe & $1.04 \times 10$ \\
6 & Afe & $1.3 \times 10^{5}$ \\
7 & Afe & $1.4 \times 10^{5}$ \\
8 & Afe & $1.72 \times 10^{5}$ \\
9 & Afe & $1.1 \times 10^{5}$ \\
10 & Afe & $1.8 \times 10^{5}$ \\
11 & Bbe & $4.88 \times 10^{5}$ \\
12 & Bbe & $1.84 \times 10$ \\
13 & Bbe & $5.4 \times 10^{5}$ \\
14 & Bbe & $1.32 \times 10^{5}$ \\
15 & Bbe & $2.4 \times 10^{5}$ \\
16 & Bfe & $1.6 \times 10^{5}$ \\
17 & Bfe & $2.64 \times 10^{5}$ \\
18 & Bfe & $1.0 \times 10^{5}$ \\
19 & Bfe & $2.1 \times 10$ \\
20 & Bfe & $5.8 \times 10^{5}$ \\
\hline$d f 10$ & $b a y n$ & \\
10 &
\end{tabular}

Abe, bacteria isolated from hayin gada market; Afe, fungi isolated from hayin gada market; Bbe, bacteria isolated from wednesday market; $\mathrm{Bfe}$, fungi isolated from wednesday market; $\mathrm{e}$, third test tube of serial dilution.

Table 2 Frequency of occurence of bacteria and fungi isolates from the spoilt onions around dutsin-ma

\begin{tabular}{lll}
\hline Organisms & $\begin{array}{l}\text { Number of } \\
\text { occurence }\end{array}$ & $\begin{array}{l}\text { Percentage (\%) } \\
\text { of occurrence }\end{array}$ \\
\hline Bacillus sp & 4 & 12.5 \\
Pseudomonas sp & 3 & 9.38 \\
Staphylococcus sp & 6 & 18.75 \\
Esherichia coli & 8 & 25 \\
Mucor & 2 & 6.25 \\
Yeast & 3 & 9.38 \\
Aspergillus sp & 6 & 18.75 \\
Total & 32 & 100
\end{tabular}

Table 3 Biochemical test for bacteria isolated and identified

\begin{tabular}{llllllll} 
Organisms & $\begin{array}{l}\text { Gram } \\
\text { RXN }\end{array}$ & CAT & MOT & MR & IND & CIT & COA \\
\hline $\begin{array}{l}\text { Bacillus sp } \\
\text { Staphylococcus }\end{array}$ & + SR & + & - & - & - & - & + \\
sp & $+C$ & + & - & - & - & - & + \\
$\begin{array}{l}\text { Pseudomonas } \\
\text { sp }\end{array}$ & $-\mathrm{LR}$ & + & + & - & - & + & - \\
Esherichia coli & $-R$ & + & + & + & + & - & -
\end{tabular}

+C, gram positive cocci; -, negative; +, positive; -R, gram negative rod; +R, gram positive rod; CAT, catalase; MO, motility; IND, indole; CIT, citrate; COA, coagulase; Gram RXN, gram reaction; MR, methyl red.

Table 4 Identification and characterization of fungi isolated

\begin{tabular}{lll}
\hline Organisms & Microscopic & Macroscopic \\
\hline Mucor & $\begin{array}{l}\text { Thick non-septate hyphae } \\
\text { with dark sporongiospore }\end{array}$ & $\begin{array}{l}\text { White, heavy, woolyfluffy } \\
\text { growth covering entire plate }\end{array}$ \\
Aspergillus sp & $\begin{array}{l}\text { Thick septate hyphae with } \\
\text { conidiaborn in chains from } \\
\text { the sterigmata }\end{array}$ & $\begin{array}{l}\text { Black colonies with white } \\
\text { edges }\end{array}$ \\
Yeast & $\begin{array}{l}\text { Oval in shape with very } \\
\text { short Multilateral budding }\end{array}$ & $\begin{array}{l}\text { Small Creamy or Whitish } \\
\text { colonies }\end{array}$ \\
\hline
\end{tabular}

Table 5 Antibiotics sensitivity pattern of bacterial isolates obtained from the spoilt onions antibiotics used on bacterial isolates

\begin{tabular}{llllllllll}
\hline CH & CN & AM & PEF & OFX & S & AU & SXT & SP & CPX \\
\hline 11 & 22 & 24 & 25 & 10 & 24 & 10 & 20 & 6 & 34 \\
5 & 6 & 3 & 4 & 7 & 2 & 1 & 10 & 5 & 4 \\
23 & 30 & 31 & 31 & 32 & 32 & 32 & 25 & 32 & 34 \\
25 & 23 & 28 & 26 & 38 & 27 & 25 & 8 & 30 & 31
\end{tabular}

Greater than $19 \mathrm{~mm}$, susceptible; Less than $13 \mathrm{~mm}$, resistance; $\mathrm{CH}$, chloramphenicol; $\mathrm{SXT}$, septrin;Am, amoxicillin; $\mathrm{CN}$, gentamicin; $\mathrm{S}$, streptomycin; OFX, tarivid;Au, augmentin;AM, amoxicillin; PEF, pefloxacin; SP, sparfloxacine.

\section{Discussion}

In the present study, the microorganisms isolated were Staphylococcus sp, Bacillus sp, Pseudomonas sp, Esherichia coli, Mucor, Yeast and Aspergillus sp. Growth on mould was identified on sabourand agar and most of the isolated bacteria grew on Nutrient agar. This was because sabourand agar contains antibiotics, which makes it bacteriostatic, thereby inhibiting the growth of bacteria. On the other hand nutrient agar contains antimycotic agent, which inhibit the growth of fungi. The fungal organisms isolated were Aspergillus sp, Mucor and Yeast. This research agree with that of Baiyewu et al. ${ }^{21}$ who isolated these fungi from garlic, pawpaw fruits in Nigeria, Krogh (1992) who also isolated seven different fungal genera including the one isolated from this research from different fruits including sweet orange and when these isolates were aseptically inoculated into healthy susceptible fruits, the characteristic symptoms originally observed were also noticed. All the three organisms isolated successfully take part in decay and are thus confirmed as the causal organisms of fruit decay. ${ }^{20}$ This research also agrees with Shehu et al. ${ }^{22}$ who reported a high frequency of occurrence for Aspergillus sp in the onion bulbs they studied. The presence of these fungi in the 
onion bulbs is attributable to the environmental conditions, handling and processing, storage of the onions, and the quality of the onion bulbs. ${ }^{16}$ These fungi have been known to cause diseases of human and animals like Ring worm and Aspergillosis which come from the air, wind, water, soil and even the handler. They are the sources of highly potent mycotoxins which are hazardous to health. ${ }^{17}$ The presence of these fungi in significant numbers in onion bulbs is therefore a public health risk. ${ }^{17}$ This result also agrees with Samuel et al. ${ }^{17}$ who isolated six different fungi including Aspergillus sp, which is the highest frequency of occurrence in the onion bulbs they studied. Dimkpa et al..$^{23}$ also implicated fungi as contaminants of many agricultural commodities including onions. Narayana et al. ${ }^{24}$ reported Aspergillus sp as the causative agent of black mold rot of onions.

The findings from the present investigation indicates that the aforementioned fungi were associated with deterioration of onion bulbs, this agrees with the reports of ${ }^{15,23}$ and that fungi constitute a menace in the storage of many agricultural commodities including fruits, vegetables and nuts. ${ }^{22}$ The bacteria isolated were Staphylococcus $\mathrm{sp}$, Bacillus sp, pseudomonas sp, and Esherichia coli. Bacillus sp is known to cause food poisoning. This agrees with Liao and Wells ${ }^{25}$ who isolated four different bacteria, Bacillus sp, Staphylococcus sp, Erwinia sp, pseudomonas sp, and Xanthomonas compestris. Roopa et al. ${ }^{26}$ isolated three different bacteria responsible for causing onion spoilage which include Staphylococcus sp, Bacillus sp, and Erwinia $\mathrm{sp}$, Staphylococcus sp had the highest frequency of occurrence and therefore it is responsible for causing onion spoilage because it is normal flora of the body, it can be found in the skin, nose and throat.

\section{Conclusion}

The result of this research show that spoilt onion bulb is a reservoir of both fungal and bacterial microorganisms which have been known to cause spoilage. Some of the organisms isolated Pseudomonas sp, Bacillus sp and Esherichia coli were sensitive to Chloramphenicol, Septrin, Amoxicillin, Gentamicin, Streptomycin, Tarivid, Augmentin, Pefloxacin, Sparfloxacine, and Ciprofloxacin, antibiotics while Staphylococcus sp was resistant to the antibiotics. Contamination could also be due to exposure of the onions to poor environmental conditions such as humidity and temperature

\section{Recommendation}

i) Maintain dry conditions during harvesting, onion bulbs should be handled gently to avoid bruises. During irrigation, avoid use of microbial contaminated water to avoid infestation.

ii) Good storage facility of the onion bulbs should be provided.

iii) Consumption of raw onion without prior heat treatment should be discouraged.

\section{Acknowledgements}

None.

\section{Conflict of interest}

The author declares no conflict of interest.

\section{References}

1. Rose P, Whiteman M, Moore PK, et al. Bioactive S-alk(en)yl cysteine sulfoxide metabolites in the genus Allium: the chemistry of potential therapeutic agents. Nat Prod Rep. 2005;22(3):351-368.
2. Yin MC, Cheng WS. Antioxidant activity of several allium members. Journal of Agricultural and Food Chemistry. 1998;46(10):4097-4101.

3. Lanzotti V. The analysis of Onion and Garlic. J Chromatogr A. 2006;21(12):3-22.

4. Krest I, Keusgen M. Biosensoric flowthrough method for the determination of cysteine sulfoxides. Analytica Chimica Acta. 2002;469(2):155-164.

5. Ioku K, Aoyama Y, Tokuno A, et al. Various cooking methods and the flavonoid content in onion. J Nutr Sci Vitaminol (Tokyo). 2001;47(1):7883.

6. Fossen T, PedersenAT, Andersen OM. Flavonoids from red onion (Allium cepa). Phytochemistry. 1998;47(2):281-285.

7. Viuda MY, Fernández LJA. Antibacterial Activity of Different Essential Oils Obtained from Spices widely used in Mediterranea Diet. International Journal of Food Science, Internationale and Technology. 2008;43(3):526-531.

8. Xu HX, Lee SF. Activity of plant flavonoids against antibiotic-resistant bacteria. Phytother Res. 2001;15(1):39-43.

9. Grohs BM, Kunz B. Use of spice mixtures for the stabilization of fresh portioned pork. Food Control. 2000;11(6):433-436.

10. Navas PB, Carrasquero A, Flores I. Effect of Black Tea, Garlic and Onion on Corn Oil Stability and Fatty Acid Composition under Accelerated Oxidation. International Journal of Food Science and Technology. 2006;41(3):243-247.

11. Uzeh RE, Alade FA, Bankole M. The microbial quality of pre-packed mixed vegetable salad in some retail outlets of lagos, Nigeria. African Journal of Food science. 2009;3(9):270-272.

12. Adebajo LO, Diyaolu SA. Mycology and spoilage of retail cashew nuts. African Journal of Biotechnology. 2003;2(10):369-373.

13. Tyson JL, Fullerton RA. Effect of soil borne-inoculum on incidence of onion black mould (Aspergillus niger). New Zealand Plant Protection. 2004;57:138-141.

14. Muhammed S, Shehu K, Amusa NA. Survey of the market diseases and aflatoxin ccontamination of fruits and vegetables in Sokoto, North western, Nigeria. Nutrition and Food science. 2004;34(2):72-76.

15. Raju K, Naik MK. Effect of pre-harvest spray of fungicides and botanicals on storage diseases on onion. Indian Phyto-Pathology. 2006;59(2):133-141.

16. Samuel O, Ifeanyi O. Fungi associated with the deterioration of post harvest onion bulb sold in some markets in Awka, Nigeria. Journal of Bioengineering and Bioscience. 2015;3(5):90-94.

17. Federal Republic of Nigeria. National population commission census. Nigeria: The federal Government Printers; 2006. p. 1-64.

18. Oyeleke SB, Manga BS. Essentials of laboratory practicals microbiology. Minna: Tobest pub; 2008. p. 36-70.

19. Cheesbrough M. District laboratory practice in tropical countries. 2nd ed. USA: Cambridge University Press; 2006. p. 1-442.

20. Baiyewu RA, Amusa NA, Ayoola OA, et al. Survey of the postharvest disease and aflatoxin contamination of marketed pawpaw fruit (Carica papaya L.) in South Western Nigeria. African Journal of Agricultural Research. 2007;2(4):178-181.

21. Shehu K, Muhammad S. Fungi associated with the storage rots of onion bulb in Sokoto Nigeria. International journal of modern Botany. 2011;1(1):1-3.

22. Dimkpa SON, Onuegbu BA. Mycoflora of copra and effect of bringing on some properties of copra in Nigeria. Agriculture and Biology Journal of North America. 2010;1(3):391-394. 
23. Narayana KJP, Srikanth M, Vijayalakshmi M, et al. Toxic spectrum of aspergilus Niger causing black mold rot of onions. Research Journal of Microbiology. 2007;2(11):881-884.

24. Liao CH, Wells JM. Association of pectolytic strain of xanthomonas compestris with soft rots of fruits and vegetables at retail markets. Phytopathology. 1987;77(3):418-422.
25. Roopa V, Suvarna VC, Natesh N. Antimicrobial activity of plant extracts against post harvest spoilage of onion. In J current Microbiol and App Sci.2014;3(5):388-394.

26. Shahedur R, Anowar KP, Rezuanul I, et al. Antibacterial activity of natural spices on multiple drug resistant esherichia coli isolated from drinking Water, Bangladash. Ann Clin Microbiol Antimicrob. 2011;10:10. 